\title{
Development and In vitro Evaluation of Self-Adhesive Matrix-Type Transdermal Delivery System of Ondansetron Hydrochloride
}

\author{
Sheba Rani Nakka David ${ }^{1,2 *}$, Rajan Rajabalaya ${ }^{1,2}$ and Eu Sheau Zhia ${ }^{1}$ \\ ${ }^{1}$ Institute of Health Sciences, Universiti Brunei Darussalam, Jalan Tungku Link, BE1410, Negara Brunei Darussalam, \\ ${ }^{2}$ International Medical University, No. 126, Jalan Jalil Perkasa 19, Bukit Jalil 57000, Kuala Lumpur, Malaysia \\ *For correspondence: Email: sdsheba@gmail.com; Tel: +673 246 3001; Fax: +673 2463001
}

Received: 22 April 2014

Revised accepted: 18 December 2014

\begin{abstract}
Purpose: To develop and evaluate self-adhesive matrix-type ondansetron hydrochloride (OND) transdermal formulation.

Methods: OND transdermal patches were prepared using solvent casting method. The matrix polymer composition was Eudragit E 100, polyvinyl pyrrolidone and either propylene glycol or dibutyl sebacate as plasticizer. Mean patch thickness, tensile strength, moisture content, water absorption capacity and drug content of the patches were studied. In vitro release and permeation of the patches were determined using Franz diffusion cell.

Results: Mean patch thickness, moisture content, and water uptake increased with increased contents of polyvinyl pyrrolidone (PVP) and plasticiser. Higher levels of PVP and plasticiser increased drug release. Addition of release modifier such as succinic acid (SA) and myristic acid (MA) to the patch formulations produced a significant increase in drug release from the patch. Higuchi plots for patches containing propylene glycol $(P G)$ were non-linear $\left(r^{2}=0.9564\right)$, indicating that they did not follow Higuchi release model whereas the plots for most of the patches containing dibutyl sebacate (DBS) followed Higuchi release model $\left(r^{2}=0.9974\right)$.

Conclusion: DBS is a superior plasticiser to $P G$ for OND matrix patches while succinic acid (SA) is a more effective release modifier than myristic acid (MA) for PG patches.
\end{abstract}

Keywords: Ondansetron hydrochloride, Drug release, Release modifier, Transdermal, Dibutyl sebacate, Succinic acid, Higuchi model, Plasticizer

Tropical Journal of Pharmaceutical Research is indexed by Science Citation Index (SciSearch), Scopus, International Pharmaceutical Abstract, Chemical Abstracts, Embase, Index Copernicus, EBSCO, African Index Medicus, JournalSeek, Journal Citation Reports/Science Edition, Directory of Open Access Journals (DOAJ), African Journal Online, Bioline International, Open-J-Gate and Pharmacy Abstracts

\section{INTRODUCTION}

Chemotherapy-induced nausea and vomiting (CINV) is a common side effect encountered by cancer patients during chemotherapy treatment. Ondansetron is a serotonin subtype $3(5-\mathrm{HT} 3)$ receptor antagonist used in CINV management. Orally administered OND undergoes extensive hepatic first-pass metabolism, which accounts for its low bioavailability and short half-life [1]. It tends to be vomited before being absorbed and has limited use in patients with difficulty swallowing after chemotherapy [2,3]. Polymers act as the backbone of systems for transdermal delivery and promote drug release in a predesigned manner. Plasticiser is added to improve flexibility, thus reducing patch brittleness [4-7]. OND was selected as the model candidate for this study because it possesses several ideal characteristics for transdermal delivery system such as low molecular weight and the desired range of $\log P, P k a$ value and melting point [8]. 
Gwak et al investigated the effects of vehicles on in vitro permeation of OND liquid formulations across mouse skin and found that ethanol and water were the most effective vehicles [9]. However, they do not mix well with pressuresensitive adhesive (PSA) and so a further study was carried out using different vehicles to develop OND transdermal PSA matrix formulations [10]. Krishnaiah et al prepared hydroxypropyl cellulose gel drug reservoir formulations of OND and evaluated the effect of menthol (a penetration enhancer) on drug permeation across rat epidermis. Pattnaik et al reported that chloroform was a preferred casting solvent for OND in transdermal films [10]. OND matrix type transdermal patches were prepared by Swain et al using different ratios of ethyl cellulose (EC) and polyvinylpyrrolidone (PVP) polymers [2].

The objective of this study was to develop the transdermal formulation of OND with a capacity to provide the required therapeutic drug concentration.

\section{EXPERIMENTAL}

\section{Materials}

Ondansetron hydrochloride (OND) was a gift from Aurobindo Chemicals, India. Eudragit E100 was a gift from Evonik Rohm GmbH Pharma Polymers, Germany. Polyvinylpyrrolidone (PVP, K-30) was purchased from BASF Chemical Company, Germany. Propylene glycol (PG) and succinic acid (SA) were purchased from Merck Chemicals, Germany while dibutyl sebacate (DBS) was obtained from Sigma-Aldrich Chemie $\mathrm{GmbH}$, Riedstr, Germany. Myristic acid and eugenol were purchased from Spectrum Chemical Mfg Corp, USA. All the solvents used were of analytical reagent grade.

\section{Preparation of the patches}

The composition of the patches are shown in Table 1. The patches were prepared by dissolving $500 \mathrm{mg}$ Eudragit E100 in $3 \mathrm{~mL}$ chloroform followed by addition of PVP with slow, uniform magnetic stirring at room temperature. Plasticiser (either PG or DBS) and $16 \mathrm{mg}$ OND was added to the solution and stirred for $15-20$ min. Release modifier (either SA or MA) was then incorporated. Finally, eugenol was added and the solution stirred for $30 \mathrm{~min}$, poured slowly into the centre of a stainless steel ring with aluminium foil as a backing layer, and then dried at room temperature for $24 \mathrm{~h}$.

\section{Determination of patch thickness}

Patch thickness was measured using a digital micrometer (Mitutoyo, Japan). A mean of six readings was obtained. The results reported a mean of six measurements (Table 1).

\section{Determination of tensile strength}

The tensile strength of the patches was evaluated using Instron 4204 Tensile tester, with a $50 \mathrm{KN}$ load cell (Instron, UK). Six samples of each formulation were tested at an extension speed of $5 \mathrm{~mm} / \mathrm{min}$ [18]. The test was carried out at $25 \pm 2{ }^{\circ} \mathrm{C}$ and $56 \pm 2 \% \mathrm{RH}$ and tensile strength calculated as in Eq 1 .

$T=L_{\text {max }} / A_{i}$

where $T$ is the tensile strength; $L_{\max }$ is the maximum load; and $A_{i}$ is the initial cross sectional area of the sample. The results are reported as mean of six readings (Table 1 ).

\section{Evaluation of drug content}

A known area of each patch was weighed accurately and dissolved in $2 \mathrm{~mL}$ chloroform followed by dilution with distilled water and then filtered. Drug content was analysed by UV spectrophotometer (PerkinElmer, USA) at 249 $\mathrm{nm}$. A drug-free film was used as control. A mean of three readings was recorded. The results are reported as mean of six readings (Table 2).

\section{Measurement of moisture content}

Each patch was weighed and kept in a desiccator containing fused calcium chloride at $40{ }^{\circ} \mathrm{C}$ for $24 \mathrm{~h}$. The patches were reweighed until a constant weight was obtained. A mean of three readings was taken. The results are reported as mean of six readings (Table 2 ).

\section{Water absorption studies}

Each patch was weighed and kept at room temperature for $24 \mathrm{~h}$ with exposure to two relative humidities of $75 \%$ (containing saturated sodium chloride solution) and $93 \%$ (containing saturated ammonium hydrogen phosphate solution) in different desiccators. The patches were reweighed until a constant weight was obtained. A mean of three readings was recorded. The results are reported as mean of six readings (Table 2 ). 


\section{In vitro release studies}

In vitro release studies were carried out in a Franz diffusion cell (PermeGear, USA). A piece of circular matrix patch about $3 \mathrm{~cm}^{2}$ was mounted on receptor compartment, which was filled with freshly prepared phosphate buffered saline $(\mathrm{pH}$ 7.4). Temperature was maintained at $32 \pm 0.5$ ${ }^{\circ} \mathrm{C}$. A sample $(0.5 \mathrm{~mL})$ was withdrawn every hour for $8 \mathrm{~h}$ and replaced immediately with the same volume of saline solution. The withdrawn samples were diluted and analysed by UV spectrophotometry at $249 \mathrm{~nm}$ [Shimadzu UV1700 , UK]. A mean of three readings was recorded (Table 3 ).

\section{In vitro permeation studies}

A matrix patch was bound intimately with a section of freshly excised albino mouse abdominal skin on the receptor compartment. The skin's dermal side was kept in contact with the receptor liquid at all times to ensure continuous drug permeation. All other analysis conditions were similar to those used for in vitro release studies above. A mean of three readings was recorded (Table 3 ).

\section{Attenuated total reflectance-Fourier transform infrared (ATR-FTIR) studies}

The patches were analyzed by attenuated total reflectance-Fourier transform infrared (ATRFTIR) studies on a Magma-IR ${ }^{\text {TM }}$ Spectrometer 750 (Nicolet Instrument Corp.), equipped with a Golden Gate Single Reflection Diamond ATR. Spectra were recorded on mean of 32 scans of transdermal patch at a resolution of $4 \mathrm{~cm}^{-1}$ and in the frequency range of $400-4000 \mathrm{~cm}^{-1}$.

\section{Statistical analysis}

The results obtained were treated statistically using one-way analysis of variance (ANOVA).
Post-hoc Tukey-HSD (Honestly Significant Difference) test was performed when there was a statistically significant difference, which was set at $p \leq 0.05$.

\section{RESULTS}

\section{Physicochemical and mechanical characteris- tics of patches}

The mean thicknesses of the films varied from 0.08 to $0.18 \mathrm{~mm}$ while mean tensile strength ranged from 4.36 to $6.93 \mathrm{MPa}$. Transdermal patches with a combination of lower thickness, higher tensile strength, optimal range of peel adhesion value (40 to $200 \mathrm{cN} / \mathrm{cm})$ were subjected to in vitro release and permeation studies.

\section{Moisture content, water absorption and drug content}

Table 3 shows that the mean content of OND in all the patches was > $99 \%$ while moisture content and water absorption capacity were dependant on type and concentration of plasticizer used in the study. Since patch with too much of water is prone to microbial growth while too less amount of water is prone to cracking and chances to absorb water from our skin. From the Table 2 it is clear that PG containing patches have higher percentage of moisture content and water absorption ( $>1)$ compare to DBP containing patches but drug contents of both the categories are equally distributed. Therefore, it is important to perform physicochemical studies in order to determine the suitable patch therapy over longer period of time without losing integrity of the polymeric composition of the transdermal patches.

Table 1: Mean thickness and tensile strength of patches

\begin{tabular}{|c|c|c|c|c|c|c|}
\hline Patch code & PVP (mg) & $\begin{array}{r}\text { Plasti } \\
(\%\end{array}$ & & $\begin{array}{c}\text { Mean thickness } \\
(\mathrm{mm})\end{array}$ & $\begin{array}{l}\text { Mean tensile } \\
\text { strength (MPa) }\end{array}$ & $\begin{array}{c}\text { Peel adhesion } \\
(\mathrm{cN} / \mathrm{cm})\end{array}$ \\
\hline E1 & 0 & \multirow{6}{*}{ PG } & 10 & 0.09 & $4.36 \pm 0.40$ & $242 \pm 3$ \\
\hline E2 & 0 & & 20 & 0.10 & $4.80 \pm 0.30$ & $231 \pm 12$ \\
\hline E3 & 50 & & 10 & 0.10 & $4.95 \pm 0.70$ & $114 \pm 20$ \\
\hline E4 & 50 & & 20 & 0.13 & $6.73 \pm 0.50$ & $39 \pm 2$ \\
\hline E5 & 100 & & 10 & 0.16 & $5.15 \pm 0.30$ & $37 \pm 3$ \\
\hline E6 & 100 & & 20 & 0.18 & $6.89 \pm 0.40$ & $15 \pm 0$ \\
\hline E7 & 0 & \multirow{6}{*}{ DBS } & 10 & 0.08 & $4.90 \pm 0.40$ & $287 \pm 14$ \\
\hline E8 & 0 & & 20 & 0.09 & $4.92 \pm 0.60$ & $275 \pm 7$ \\
\hline E9 & 50 & & 10 & 0.09 & $5.01 \pm 0.70$ & $209 \pm 3$ \\
\hline E10 & 50 & & 20 & 0.11 & $6.57 \pm 0.30$ & $97 \pm 5$ \\
\hline E11 & 100 & & 10 & 0.13 & $5.69 \pm 0.20$ & $88 \pm 4$ \\
\hline E12 & 100 & & 20 & 0.15 & $6.93 \pm 0.50$ & $41 \pm 8$ \\
\hline
\end{tabular}

Note: For all formulations, the Eudgragit :OND ratio was $500: 16(\mathrm{mg})$ 
Attenuated total reflectance-Fourier transform infrared (ATR-FTIR) spectra

A comparison of the ATR-FTIR spectra of the individual patch components (Eudragit E 100, PVP and OND) as well as the patch itself is presented in Figure 1. The FTIR spectra of the formulation containing E 100: PVP: OND showed all the peaks for the polymers. The characteristic peaks of E 100 and PVP were observed at $2953 \mathrm{~cm}^{-1}$ and $1723 \mathrm{~cm}^{-1}, 1653 \mathrm{~cm}^{-1}, 1657 \mathrm{~cm}^{-1}$, $1641 \mathrm{~cm}^{-1}, 1437 \mathrm{~cm}^{-1}$, and $843 \mathrm{~cm}^{-1}$ respectively. No significant shifts in the peaks corresponding to the drug or polymers were observed in the formulation matrix. Some characteristic peaks corresponding to the drug were found to overlap those of the polymer.

\section{In vitro drug release}

The results of cumulative percent release, release rate $\left(\mu \mathrm{gm} / \mathrm{cm}^{2} / \mathrm{hr}\right)$ and drug release kinetics after 8 hours are shown in Table 3 and Figures 2 and 3 , respectively. The regression correlation, $r^{2}$ value for release kinetic models for all formulations was given in Table 5 .

Table 2: Moisture content, water absorption capacity, and mean drug content of patches

\begin{tabular}{|c|c|c|c|c|}
\hline \multirow{2}{*}{$\begin{array}{l}\text { Patch } \\
\text { Code }\end{array}$} & \multirow{2}{*}{ Moisture content (wt \%) } & \multicolumn{2}{|c|}{ Water absorption (wt \%) } & \multirow{2}{*}{$\begin{array}{c}\text { Mean drug content } \\
(\mu \mathrm{gm} / \mathrm{cm} 2)\end{array}$} \\
\hline & & $75 \%$ RH & $93 \%$ RH & \\
\hline E1 & $1.43 \pm 0.14$ & $1.63 \pm 0.37$ & $1.75 \pm 0.26$ & $426.12 \pm 7.15$ \\
\hline E2 & $1.62 \pm 0.12$ & $1.76 \pm 0.12$ & $1.82 \pm 0.14$ & $426.36 \pm 4.89$ \\
\hline E3 & $1.75 \pm 0.50$ & $1.82 \pm 0.17$ & $1.96 \pm 0.10$ & $426.43 \pm 6.82$ \\
\hline E4 & $2.03 \pm 0.38$ & $2.08 \pm 0.19$ & $2.14 \pm 0.20$ & $426.56 \pm 9.69$ \\
\hline E5 & $2.42 \pm 0.27$ & $2.31 \pm 0.27$ & $2.48 \pm 0.17$ & $426.63 \pm 8.37$ \\
\hline E6 & $2.74 \pm 0.13$ & $2.65 \pm 0.30$ & $2.95 \pm 0.11$ & $427.26 \pm 7.48$ \\
\hline E7 & $1.02 \pm 0.25$ & $1.05 \pm 0.07$ & $1.15 \pm 0.09$ & $426.18 \pm 6.62$ \\
\hline E8 & $1.08 \pm 0.43$ & $1.08 \pm 0.09$ & $1.18 \pm 0.06$ & $426.28 \pm 11.93$ \\
\hline E9 & $1.16 \pm 0.19$ & $1.14 \pm 0.10$ & $1.44 \pm 0.13$ & $426.51 \pm 13.05$ \\
\hline E10 & $1.21 \pm 0.20$ & $1.19 \pm 0.03$ & $1.76 \pm 0.20$ & $426.21 \pm 8.60$ \\
\hline E11 & $1.32 \pm 0.19$ & $1.28 \pm 0.09$ & $1.83 \pm 0.16$ & $426.42 \pm 9.02$ \\
\hline E12 & $1.51 \pm 0.21$ & $1.34 \pm 0.12$ & $2.04 \pm 0.18$ & $426.43 \pm 5.81$ \\
\hline
\end{tabular}

Table 3: Cumulative drug release and release rate at $8 \mathrm{~h}$ with or without release modifier

\begin{tabular}{|c|c|c|c|c|c|c|}
\hline \multirow{3}{*}{$\begin{array}{l}\text { Patch } \\
\text { code }\end{array}$} & \multicolumn{3}{|c|}{ Drug release (\%) } & \multicolumn{3}{|c|}{ Release rate $(\mu \mathrm{g} / \mathrm{cm} 2 / \mathrm{h})$} \\
\hline & \multirow{2}{*}{ - } & \multicolumn{2}{|c|}{ Release modifier (4\%) } & \multirow{2}{*}{-} & \multicolumn{2}{|c|}{ Release modifier (4\%) } \\
\hline & & $\mathbf{S}$ & M & & $\mathbf{S}$ & $\mathbf{M}$ \\
\hline E1 & 5.92 & 41.29 & 19.43 & 2.86 & 13.92 & 1.70 \\
\hline E2 & 10.84 & 54.34 & 22.19 & 0.02 & 10.66 & 23.92 \\
\hline E3 & 7.27 & 44.63 & 28.80 & 1.73 & 16.21 & 14.33 \\
\hline E4 & 16.53 & 54.67 & 31.81 & 1.94 & 9.07 & 14.83 \\
\hline E5 & 14.54 & 45.51 & 34.04 & 1.32 & 10.18 & 14.72 \\
\hline E6 & 18.06 & 57.27 & 38.27 & 1.08 & 11.38 & 7.10 \\
\hline E7 & 26.32 & - & 29.91 & 8.52 & - & 6.29 \\
\hline E8 & 29.98 & - & 30.15 & 9.76 & - & 5.72 \\
\hline E9 & 37.66 & - & 38.88 & 12.09 & - & 32.10 \\
\hline E10 & 42.85 & - & 43.58 & 20.74 & - & 21.57 \\
\hline E11 & 48.57 & - & 42.53 & 10.84 & - & 16.90 \\
\hline E12 & 47.66 & - & 43.86 & 15.21 & - & 14.10 \\
\hline
\end{tabular}




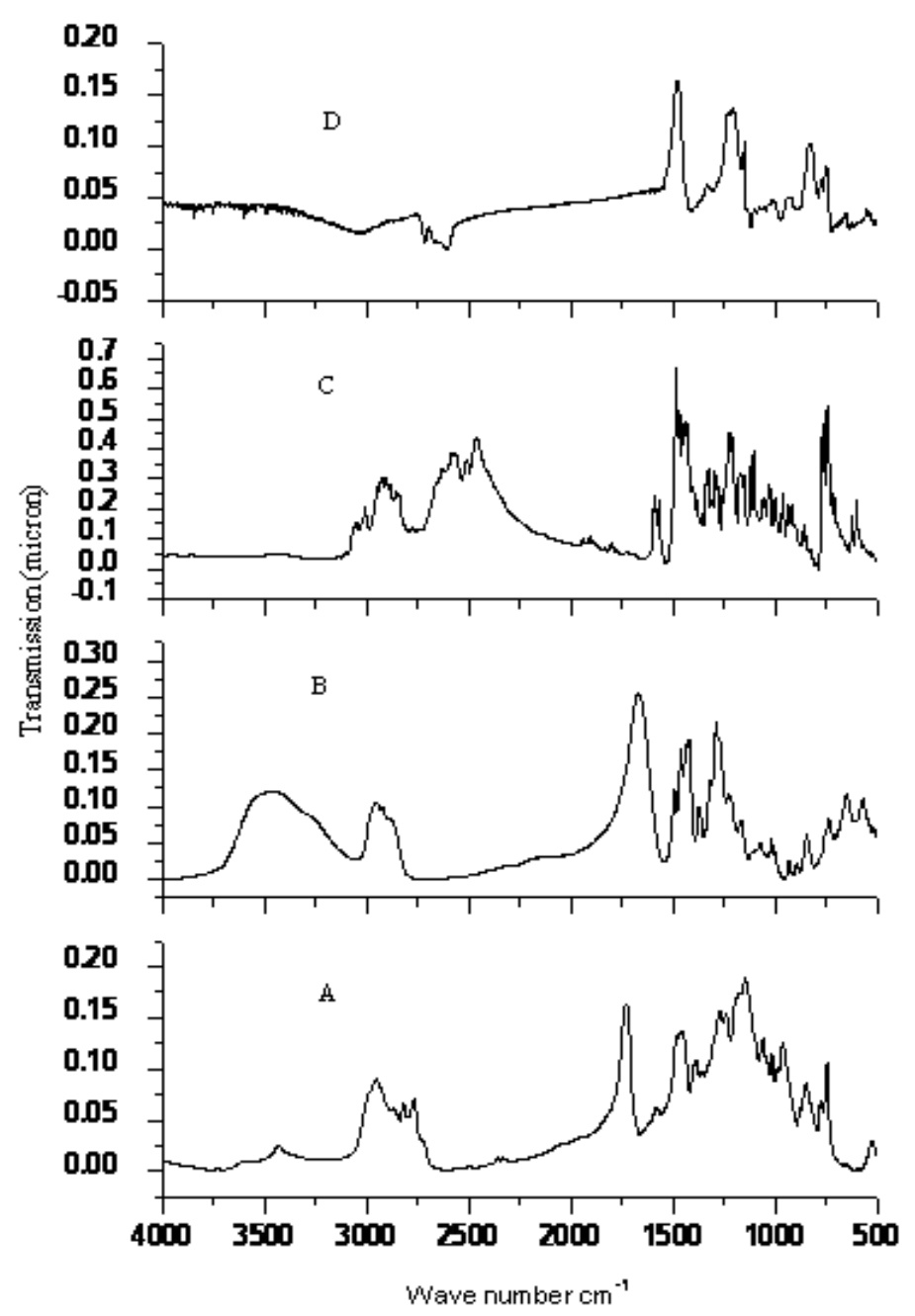

Figure 1: ATR - FTIR spectra of patch and patch components. A: Eudragit E 100, B: poly vinyl pyrrolidone, C: pure Ondansetron $\mathrm{HCl}, \mathrm{D}$ : E 100:PVP:OND matrix patch

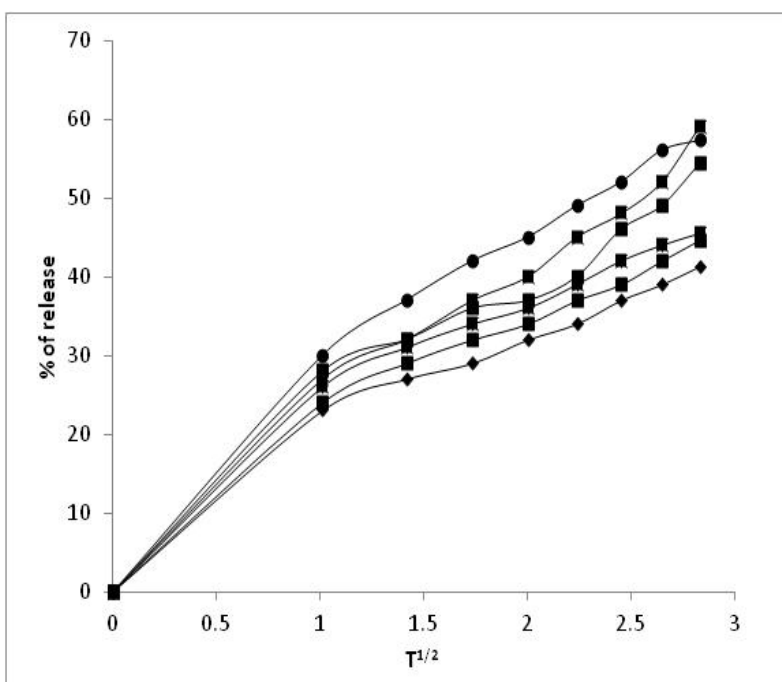

Figure 2: Release profile of PG containing patches. Key: Formulations E $1(\bullet)$, E 2 (घ), E $3(\mathbf{\Delta})$, E 4 (x), E $5\left(^{*}\right)$, E $6(\bullet)$

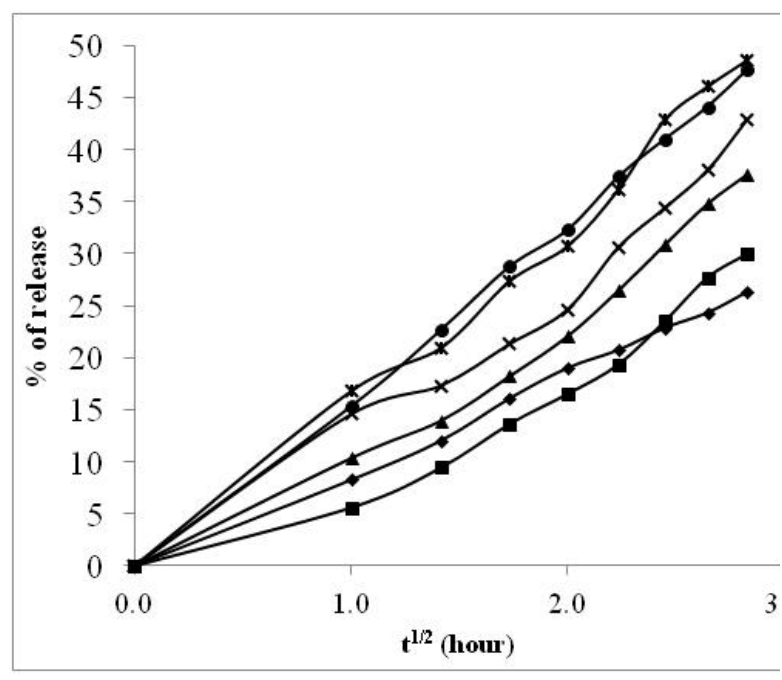

Figure 3: Release profile of DBP containing patches. Key: Formulations E 1 (•), E 2 (ロ), E $3(\mathbf{\Delta})$, E 4 (x), E $5\left(^{*}\right)$, E $6(\bullet)$ 
Table 4: Kinetic drug release data for the patches; $\mathrm{Q}=$ cumulative amount of release at $8 \mathrm{~h}$

\begin{tabular}{|c|c|c|c|c|c|c|c|c|c|}
\hline \multirow[t]{2}{*}{$\begin{array}{l}\text { Patch } \\
\text { code }\end{array}$} & \multicolumn{3}{|c|}{$\begin{array}{c}\text { Zero order: } \\
Q=k_{0} t+c\end{array}$} & \multicolumn{3}{|c|}{$\begin{array}{c}\text { Higuchi: } \\
Q=k_{\mathrm{H}} t 0.5+c\end{array}$} & \multicolumn{3}{|c|}{$\begin{array}{c}\text { Weibull distribution: } \\
\log [\ln (1 / 1-m)]= \\
\beta \log (t)-\log (a)\end{array}$} \\
\hline & $K_{\circ}$ & c & r2 & $K_{H}$ & c & r2 & $\beta$ & r2 & a \\
\hline E1 & 09.32 & 29.85 & 0.9523 & 43.92 & 02.63 & 0.8565 & 0.48 & 0.9830 & 2.59 \\
\hline E2 & 08.66 & 26.36 & 0.9543 & 40.66 & 03.58 & 0.9346 & 0.53 & 0.9353 & 2.85 \\
\hline E3 & 07.84 & 24.51 & 0.9276 & 36.21 & 04.73 & 0.9564 & 0.37 & 0.9576 & 2.29 \\
\hline E4 & 07.23 & 21.68 & 0.9189 & 29.07 & 05.61 & 0.9498 & 0.41 & 0.9879 & 5.78 \\
\hline E5 & 06.98 & 18.04 & 0.9387 & 20.18 & 07.48 & 0.9255 & 0.53 & 0.9871 & 4.62 \\
\hline E6 & 06.88 & 14.17 & 0.9254 & 19.38 & 08.06 & 0.9117 & 0.73 & 0.9837 & 5.83 \\
\hline E7 & 05.98 & 25.71 & 0.9845 & 16.34 & 06.93 & 0.9909 & 0.82 & 0.9905 & 6.92 \\
\hline E8 & 05.34 & 20.35 & 0.9775 & 14.72 & 07.48 & 0.9955 & 0.85 & 0.9826 & 7.42 \\
\hline E9 & 04.67 & 18.58 & 0.9723 & 15.83 & 08.17 & 0.9953 & 0.84 & 0.9847 & 6.39 \\
\hline E10 & 04.13 & 13.08 & 0.9545 & 19.59 & 01.85 & 0.9835 & 0.63 & 0.9798 & 5.62 \\
\hline E11 & 03.97 & 12.33 & 0.9985 & 20.83 & 06.29 & 0.9596 & 0.59 & 0.9845 & 4.93 \\
\hline E12 & 03.76 & 03.76 & 0.9753 & 15.03 & 09.73 & 0.9974 & 0.74 & 0.9974 & 7.93 \\
\hline
\end{tabular}

$t=$ time in $h r, k_{0}=$ zero order constant $; c=$ intercept, $k_{H}=$ Higuchi constant, $\beta=$ shape parameter; $a=$ scale parameter

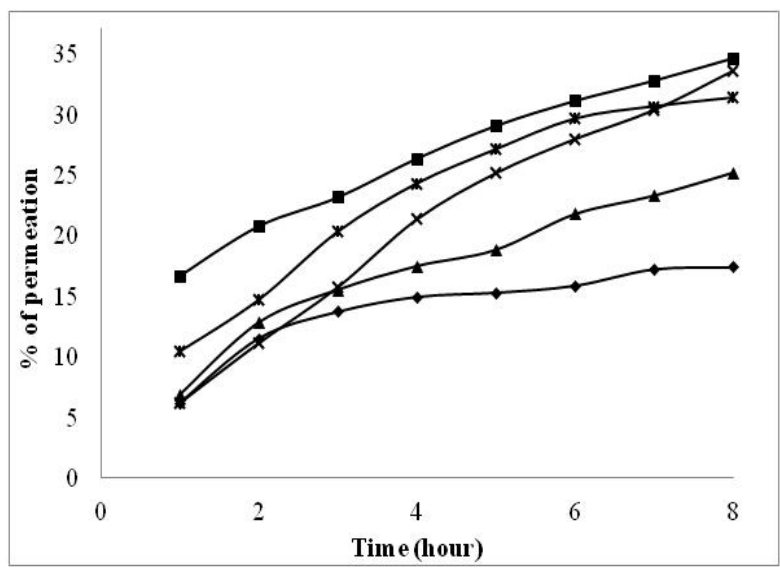

Figure 4: Release profile of PG containing patches. Key: Formulations E 2S (»), E 4 S (ロ), E 6 S (4), E 6 E $(\mathrm{x}), \mathrm{E} 6 \mathrm{ME}{\left({ }^{*}\right)}^{*}$

percentage of permeation against time in Figure 4 and 5 show a fairly constant rate of drug permeation over time, and followed concentration-dependent first-order kinetics.

\section{DISCUSSION}

According to American Society for Testing Materials (ASTM), materials with tensile strength $>$ 4.0 MPa possess an elastic characteristic [22]. Patches should be elastic in order to withstand external forces such as wear and tear during handling, storage or use [6]. There was no significant difference in the tensile strength between patches containing PG and DBS.

Higher plasticizer levels increase the free volume between polymer chains thus enabling more

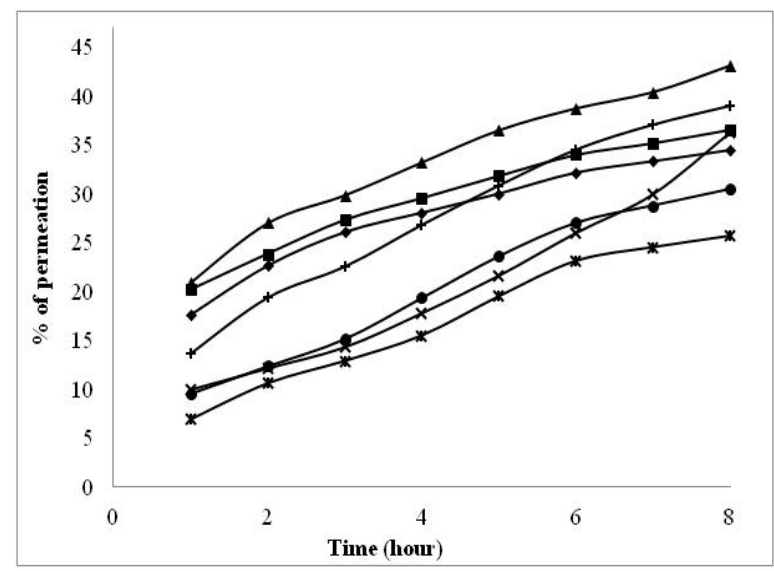

Figure 5: Release profile of DBP containing patches.

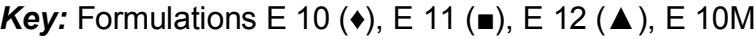
$(\mathrm{x}), \mathrm{E} 12 \mathrm{M}\left({ }^{*}\right)$, E $10 \mathrm{ME}(\bullet)$ E $12 \mathrm{ME}(\mathrm{I})$

moisture/water to be absorbed. This increases patch bulkiness and thickness, as shown in Table 1 which explains why the patches with higher plasticizer content were also thicker. Similarly, increase in plasticizer concentration also enhanced peel adhesion [22] due to softening effect exerted by the plasticizers.

Patches containing hydrophilic plasticizer (PG) showed higher moisture content and water absorption than those containing hydrophobic DBS. patches because the former allow water freely into the patch In hydrophobic nature DBS patches have difficulty to hydrate the patch during the moisture content and water absorption studies especially in higher percentages. This also explains why moisture content and water absorption capacity increased with increase in 
the content of plasticizer. This is because plasticizer can embed in between polymer chains and thus relax the chains, increasing free volume $[14,22]$. Also, PVP is hydrophilic and therefore allows water to easily diffuse into the patch, leading to higher uptake of moisture and water absorption [16]. The relatively more hydrophobic DBS-containing patches would be more difficult to hydrate and hence their lower moisture content and water absorption.

Patch thickness should also be appropriate because increased film thickness will increase compaction and reduce the mobility of molecules, which can decrease drug release from the patch [14]. Low moisture content in the formulations helps to maintain patch stability and reduce patch brittleness [4]. Besides that, water uptake should be low in order to prevent microbial contamination and decrease patch bulkiness [4].

Drug release increased with increase in the content of PVP due to the hydrophilicity of PVP which facilitates water absorption thus promoting drug dissolution and drug release from the patch [4]. Furthermore, as PVP leaches out, pores are created in the matrix for drug to diffuse out of the patch; thus, drug release is increased [4].

In an earlier report [16], it was stated that plasticizers form secondary bonds with polymer chains, which decrease inter-chain cohesive forces and increase mobility of macromolecules $[6,17]$. The higher the concentration of plasticizer in the patch, the greater the number of plasticizer molecules available to produce relaxation of polymer chains, and hence increase in drug release out of the patch [18]. Drug release was higher for patches containing DBS than those containing $P G$ because the hydrophilic nature of PG promotes water uptake which causes the plasticizer to leach out from the matrix $[17,19]$. As a result, there is a decreased amount of plasticiser to relax the polymer chains and so drug diffusion decreases [17].

When drug release was plotted against the square root of time $\left(\mathrm{t}^{1 / 2}\right)$, drug release from the patches followed a diffusion-controlled pattern. However, when the plots for patches containing PG were extrapolated to the origin, the plots were non-linear, indicating that they did not follow Higuchi release. On the other hand, the plots for patches containing DBS are were linear and thus followed Higuchi release (except for E10 and E11; Table 4). Weibull equation adequately describes the in vitro release profiles of all the transdermal formulations. The shape of the parameter, $\beta$, characterizes the curve and its $\beta$ values are $<1$ in these plots, and also have high initial slopes [19]. The values of $\beta, r^{2}$ and a are presented in Table 4 . The $\beta$ values of all the formulations were $<1$.

Incorporation of release modifiers, succinic acid (SA) or myristic acid (MA) into formulations containing $P G$ resulted in a significant increase in drug release $(p<0.05)$. This contradicts results in other studies which found that MA increased drug release while SA decreased it [20,21]. Gondaliya et al explained that SA might crosslink with Eudragit E100 to form a rigid matrix and thus retard drug diffusion from the matrix [21,23]. However, no co-polymer was added to the formulations in their study. Therefore, in the present study, it is believed that addition of PVP prevents the formation of cross-link between SA and Eudragit E100, and hence drug can diffuse freely out of the matrix.

SA produced higher drug release than MA in PGcontaining patches. This may be due to smaller molecular size of SA which enables its molecules to penetrate between polymer chains more easily and disrupt the continuity of polymer chains. As a result, matrix rigidity decreases thus increasing drug release from the patch. For patches containing DBS, SA failed to dissolve completely in the solution due to incompatibility with DBS. Besides chloroform, different solvents (acetone, methanol, and ethanol) were tested but incompatibility still occurred. Thus, no patch was generated and hence there was no significant difference between drug release before and after addition of MA for patches containing DBS.

Incorporation of eugenol produced resulted in increase in drug release for patches containing PG. However, the effect of eugenol in DBScontaining patches was not significant.

\section{CONCLUSION}

DBS is superior to $P G$ for the preparation of OND transdermal formulations in terms of mechanical and controlled release of drug over a long period of time. Furthermore, succinic acid is a suitable release modifier for OND patches containing PG. The optimised patches (E12 and E12 ME) may be further developed for actual applications by evaluating their pharmacokinetic and pharmacodynamic studies in appropriate animal models.

\section{ACKNOWLEDGEMENT}

The authors wish to express sincere gratitude to Research Laboratory of International Medical 
University for providing financial and laboratory facilities for the studies, and also to Aurobindo Chemicals, India and Evonik Rohm GmbH Pharma Polymers, Germany for the gifts of OND and Eudragit E100, respectively, as well as to the School of Bioscience and Engineering, Jadavpur University, Kolkata, India for providing facilities for mechanical studies on the transdermal patches.

\section{REFERENCES}

1. Bozigian HP, Pritchard JF, Gooding AE, Pakes GE. Ondansetron absorption in adults: effect of dosage form, food, and antacids. J Pharm Sci 1994; 83(7): 1011-1013.

2. Swain K, Pattnaik S, Sahu SC, Mallick S. Feasibility assessment of ondansetron hydrochloride transdermal systems: physicochemical characterization and in vitro permeation studies. Lat Am J Pharm 2009; 28(5): 706-714.

3. Sheth NS, Mistry RB. Formulation and evaluation of transdermal patches and to study permeation enhancement effect of eugenol. J App Pharm Sci 2011; 1(3): 96-101.

4. Gal A, Nussinovitch A. Plasticizers in the manufacture of novel skin-bioadhesive patches. Int J Pharm 2009; 370: 103-109.

5. Rajabalaya R, Khanam J, Nanda A. Design of a matrix patch formulation for long-acting permeation of diclofenac potassium. Asian J Pharm Sci 2008; 3(1): 30-39.

6. Wu C, McGinity JW. Influence of ibuprofen as a solidstate plasticizer in Eudragit ${ }^{8} R S 30 \mathrm{D}$ on the physicochemical properties of coated beads. AAPS PharmSciTech 2001; 2(4).

7. Krishnaiah YSR, Kumar MS, Raju V, Lakshmi M, Rama $B$. Penetration-enhancing effect of ethanolic solution of menthol on transdermal permeation of ondansetron hydrochloride across rat epidermis. Drug Deliv 2008; 15: 227-234.

8. Finnin BC, Morgan TM. Transdermal penetration enhancers: applications, limitations, and potential. $J$ Pharm Sci 1999; 88(10): 955-958.

9. Gwak HS, Oh IS, Chun IK. In vitro percutaneous absorption of ondansetron hydrochloride from pressure-sensitive adhesive matrices through hairless mouse skin. Arch Pharm Res 2003; 26(8): 644-648.

10. Pattnaik S, Swain K, Mallick S, Lin Z. Effect of casting solvent on crystallinity of ondansetron in transdermal films. Int J Pharm 2011; 406: 106-110.
11. Rao NGR, Suryakar VB. Formulation and evaluation of montelukast sodium mucoadhesive buccal patches for chronic asthma attacks. Int J Pharm Bio Sci 2010; 1(2): 1-14

12. Jadhav NR, Gaikwad VL, Nair KJ, Kadam HM. Glass transition temperature: basics and application in pharmaceutical sector. Asian J Pharm 2009; 3(2): 8289.

13. Setty CM, Jawarkar Y, Pathan IB. Effect of essential oils as penetration enhancers on percutaneous penetration of furosemide through human cadaver skin. Acta Pharm Sci 2010; 52: 159-168.

14. Rajabalaya R, David SRN, Khanam J, Nanda A. Studies on the effect of plasticizer on in vitro release and ex vivo permeation from Eudragit E 100 based chlorpheniramine maleate matrix type transdermal delivery system. J Excip Food Chem 2010; 1(2): 312.

15. Siepmann J, Lecomte F, Bodmeier R. Diffusion-controlled drug delivery systems: calculation of the required composition to achieve desired release profiles. J Control Rel 1999; 60: 379-389.

16. Kangarlou S, Haririan I. Physico-mechanical analysis of free ethylcellulose films plasticized with incremental weight percents of dibutyl sebacate. Iranian J Pharm Sci 2007; 3(3): 135-142.

17. Bodmeier R, Paeratakul O. Leaching of water-soluble plasticizers from polymeric films prepared from aqueous colloidal polymer dispersions. Drug Dev Ind Pharm 1992; 18(17): 1865-1882.

18. Rajabalaya R, David SRN, Khanam J, Nanada A. Studies on the effect of plasticizer on in vitro release and ex vivo permeation from Eudragit $E 100$ based chlorpheniramine maleate matrix type transdermal delivery system. J Excip Food Chem 2010; 1(2): 312.

19. Rajabalaya R, Xian TW, David SRN. Preparation and Evaluation of Transdermal Drug Delivery of Ondansetron Hydrochloride: Effect of Vegetable Oils as Permeation Enhancer. Lat Am J Pharm Sci 2012; 31(7): 1005-1012.

20. Ghosal K, Chandra A, Rajabalaya R, Chakraborty S, Nanda A. Mathematical modeling of drug release profiles for modified hydrophobic HPMC-based hydrogels. Pharmazie 2012; 67: 147-155.

21. Gondaliya $D$, Pundarikakshudu K. Studies in formulation and pharmacotechnical evaluation of controlled release transdermal delivery system of bupropion. AAPS PharmSciTech 2003; 4(1): 18-26.

22. Ganju K, Kondalkar A, Pathak AK. Formulation and evaluation of transdermal patch of colchicines with release modifiers. The Pharmacist 2007; 2(2): 21-23. 